\title{
Effect of High Water-uptake Hydrogels on the Elasticity of Kamaboko
}

\author{
Eiji Niwa,* Tian-Tsuan Wang,* Satoshi Kanoh,* \\ and Teruo Nakayama* \\ (Received October 17, 1988)
}

\begin{abstract}
In order to investigate the role of gelling substance as water absorbent, the effect of high wateruptake hydrogels on the elasticity of kamaboko was examined. Examined hydrogels were commercial graftpolymers/graftcopolymers of 1) acrylate, 2) isobutylene and maleate, 3) starch and acrylate, 4) vinylalcohol and maleate as well as highly swellable 5) Sephadex G25 and 6) polyacrylamide. The storage modulus of kamaboko was remarkably increased by 1 and 4 , somewhat increased by 2,3 and 6 , but scarcely affected by 5 . The loss modulus was somewhat increased by all the high water-uptake hydrogels except 5 . The breaking strength was increased by all of them. The breaking strain was remarkably increased by 2,5 and 6 , somewhat increased by 3 , but scarcely affected by 1 and 4 . Furthermore, expressible water of kamaboko was decreased by all of them. No correlationship was detected between their water-holding capacity and gelstrengthening action.
\end{abstract}

In these ten years, new organic hydrogels called "high water-uptake hydrogel" or "highly swellable polyelectrolyte gel" have been exploited. Most of them are graftcopolymer of polyhydric alcohols or polybasic carboxylic acids and widely applied as sanitary goods, medical supplies, food dessicants and soil conditioners because of their highly swellable character. On the other hand, it was found from the differential scanning calorimetry (DSC) analysis that the kamaboko added with profitable gelling substance contains large amount of captured water. ${ }^{1)}$ Therefore, it can be presumed that the gel-strengthening action of the gelling substance is essentially due to capture of water within the kamaboko. If so, the elasticity of kamaboko might be strengthened also by the addition of such high water-uptake hydrogels. In this paper, we describe the effect of various high water-uptake hydrogels on the elasticity of kamabokos.

\section{Materials and Method}

\section{High Water-uptake Hydrogels}

The commercial high water-uptake hydrogels were donated from their makers and tentatively named "Hydrogels 1-4" as summarized in Table 1. Moreover, highly swellable Sephadex G25 (Pharmacia) and polyacrylamide were also examined. The latter was prepared by adding $0.45 \mathrm{ml}$ of $\mathrm{N}, \mathrm{N}, \mathrm{N}^{\prime}, \mathrm{N}^{\prime}$-tetramethylethylenediamine to $300 \mathrm{~m} l$ aqueous solution of $0.075 \%$ ammonium peroxodisulfate, $22.2 \%$ acrylamide and $0.6 \% \mathrm{~N}, \mathrm{~N}^{\prime}$ methylenebisacrylamide after adjusting to $\mathrm{pH} 7.2$ with $0.5 \mathrm{M} \mathrm{Na} \mathrm{NaO}_{4}$. The resulting polyacrylamide hydrogel was coasely crushed and dehydrated at $105^{\circ} \mathrm{C}$ for $6 \mathrm{~h}$. The dehydrated gel was ground to powder in a mortal and sifted from a laboratory sieve ( $50 \mathrm{mesh}$ ). All the hydrogels were added to the fish flesh mince, surimi, as powdered form.

Table 1. Commercial high water-uptake hydrogel examined in the present study

\begin{tabular}{clll}
\hline \hline Name & Commercial name & \multicolumn{1}{c}{ Maker } & \multicolumn{1}{c}{ Materials* } \\
\hline Hydrogel 1 & Wonder Gel & Kao & Acrylate \\
Hydrogel 2 & KI Gel-201K & Kurare Isoprene Chemicals & Isobutylene and Maleate \\
Hydrogel 3 & Sanwet IM-1000 & Sanyo Chemical Industry & Starch and Acrylate \\
Hydrogel 4 & Aquareserve GP-00 & $\begin{array}{l}\text { Nippon Synthetic } \\
\text { Chemical Industry }\end{array}$ & $\begin{array}{l}\text { Vinyl Alcohol and Ester of } \\
\text { Maleic Acid }\end{array}$ \\
\hline
\end{tabular}

* Supposed from the catalogue of each hygrogel.

* Faculty of Fisheries, Mie University, Tsu 514, Japan（丹羽栄二, 王 天鑽，加納 哲，中山照雄：三重大 学水虐学部). 


\section{Kamaboko Formation}

Casing-packed kamaboko was prepared as described previously." Frozen surimi of Alaska pollack Theragra chalcogramma (Taiyo Fisheries, SA-grade) was thawed by leaving it overnight in a cold room at $4^{\circ} \mathrm{C}$, minced and ground for $10 \mathrm{~min}$ with $3 \% \mathrm{NaCl}, 30 \%$ water and 4 or $8 \%$ high wateruptake hydrogel. The resulting fish flesh paste, shio-surimi, was packed into a polyvinylidene cholride tube (diameter: $3 \mathrm{~cm}$ ), heated at $40^{\circ} \mathrm{C}$ for $30 \mathrm{~min}$ to set after sealing both ends of the tube, and reheated at $80^{\circ} \mathrm{C}$ for $20 \mathrm{~min}$ to gel. The control kamaboko was prepared without addition of the high water-uptake hydrogel. The products were preserved in a refrigerator at $4^{\circ} \mathrm{C}$.

In the sample for dynamic visco-elasticity measurement, the shoi-surimi was packed together with a substandard blade $\left(25 \times 3.5 \times 0.5 \mathrm{~mm}^{3}\right)$ into a measuring cell $\left(40 \times 15 \times 2 \mathrm{~mm}^{3}\right)$ equipped with a thermo-module unit, fixed to a rheometer (Toyoseiki, Rheolograph-sol No 653) and heated to gel at $40^{\circ} \mathrm{C}$ for $30 \mathrm{~min}$, then at $80^{\circ} \mathrm{C}$ for $20 \mathrm{~min}$.

\section{Elasticity Measurements}

The dynamic visco-elasticity measurement, compression puncture test and expressible water test were carried out as described previously.2)

In the case of the dynamic visco-elasticity measurement, the cell was vibrated at a frequency of $3 \mathrm{~Hz}$ and a strain of 0.01 after cooled to $25^{\circ} \mathrm{C}$. The shear storage and the loss moduli were automatically recorded.

In the case of the puncture test, the kamaboko was cut into cylinders (height: $1.6 \mathrm{~cm}$ ), compressed using a food rheometer at a plunger speed of $6 \mathrm{~cm} / \mathrm{min}$ (Fudoh Kogyo, NRM 2010J-CW, spherical plunger, diameter: $5 \mathrm{~mm}$ ). The breaking strength and breaking strain were read from a recording chart.

In the case of the expressible water test, a sliced sample piece (thickness: $0.5 \mathrm{~cm}$ ) was compressed between double layer of filter paper (Toyo filterpaper, No 5 ) ) at $10 \mathrm{~kg} / \mathrm{cm}^{2}$ for $20 \mathrm{sec}$. The amount of expressible water was expressed as a percentage of the weight loss of the sample during compression.

\section{Water-holding Capacity of High Water-uptake Hydrogel}

Fifty milligrams of the high water-uptake hydrogel and $10 \mathrm{ml}$ of $3 \% \mathrm{NaCl}$ solution were poured into a graduated, conical bottomed centrifuge tube, heated for the presecribed time within a water bath previously controled to $80^{\circ} \mathrm{C}$, and centrifuged at $3000 \mathrm{rpm}$ for $10 \mathrm{~min}$ after cooled with running water. Water-holding capacity of the sample was expresesd as the volume of the precipitate.

\section{Adhesive Force of High Water-uptake Hydrogel Pellet to Shiosurimi}

Thermal adhesion of the pellet of the high wateruptake hydrogel to the shio-surimi was examined as described previously. ${ }^{3}$ Sixty milligrams of the high water-uptake hydrogel was pressed to a pellet at $200 \mathrm{~kg} / \mathrm{cm}^{2}$ for $10 \mathrm{~min}$ within a pellet die for IR measurement use (JASCO, T-100). The resulting pellet (thickness: about $1 \mathrm{~mm}$ ) was gently put on the surface of the shio-surimi $(3.0 \mathrm{~g})$ flatly packed into a Petri dish, heated in an oven at $40^{\circ} \mathrm{C}$ for $1 \mathrm{~h}$ after wrapped with a plastic film, and reheated at $80^{\circ} \mathrm{C}$ for $40 \mathrm{~min}$. The adherent pellet was stretched using the above rheometer after fixed to a disk type of plunger with an instant binder (Toa Gosei Kagaku. Aron Alpha). Adhesive force was expressed as the instantaneous maximum force when the pellet was stretched by $15 \mathrm{~mm}$ at a speed of $6 \mathrm{~cm} / \mathrm{min}$. As a control, the shio-surimi was stretched after gelled within the Petri dish under the same condition.

\section{Results}

Fig. 1 shows the effect of high water-uptake hydrogels on the shear storage and the loss moduli of the kamaboko. The storage modulus was remarkably increased by Hydrogels 1 and 4 , somewhat increased by Hydrogels 2 and 3 , and polyacrylamide, but scarcely affected by Sephadex G25. The loss modulus was somewhat increased by all the high water-uptake hydrogels except for Sephadex G25.

Fig. 2 shows the same effect on the breaking strength and breaking strain of the kamaboko. The breaking strength was increased by all the high water-uptake hydrogels examined. Such the increase was accelerated with increasing the amount of the high water-uptake hydrogels added. The breaking strain was remarkably increased by Hydrogel 2, Sephadex G25 and polyacrylamide, somewhat increased by Hydrogel 3, but scarcely affected by Hydrogels 1 and 4 .

Fig. 3 shows the same effect on the amount of expressible water of the kamaboko. The amount was remarkably decreased by all the hydrogels examined and this decrease was accelerated with increasing the amount of the high water-uptake hydrogel added. 


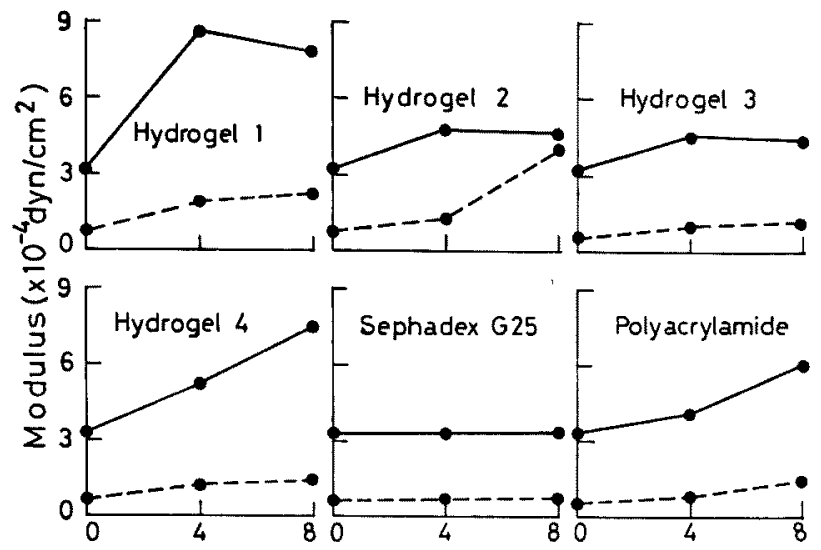

Amount of added high water-uptake hydrogel $(\%)$

Fig. 1. Effect of high water-uptake hydrogel on the storage modulus and loss modulus of kamaboko.

-0: Storage modulus, -0-: loss modulus.

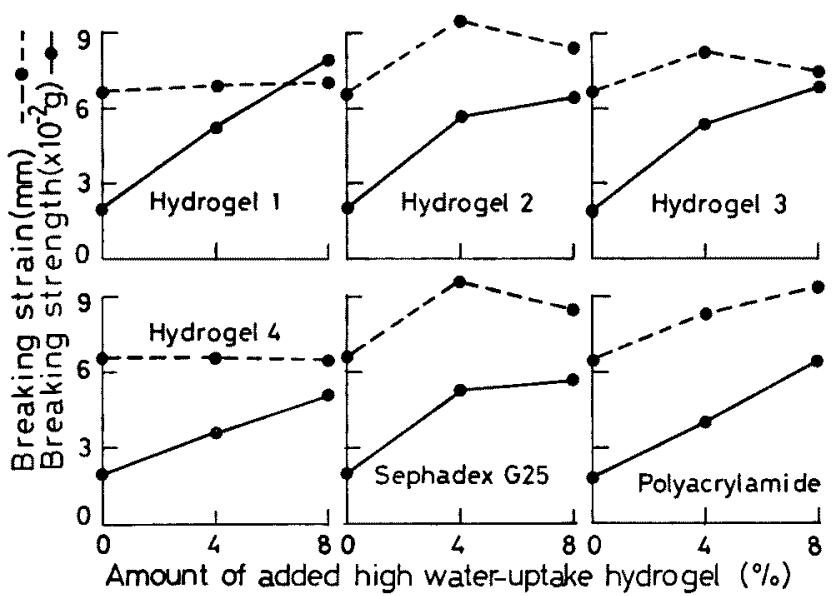

Fig. 2. Effect of high water-uptake hydrogel on the breaking strength and breaking strain of kamaboko.

-0: breaking strength, -0-: breaking strain.

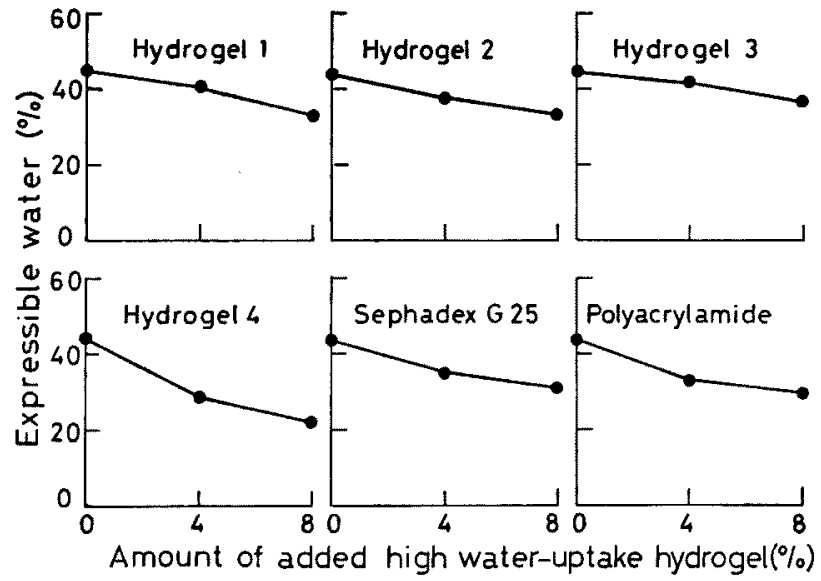

Fig. 3. Effect of high water-uptake hydrogel on the amount of expressible water of kamaboko. 


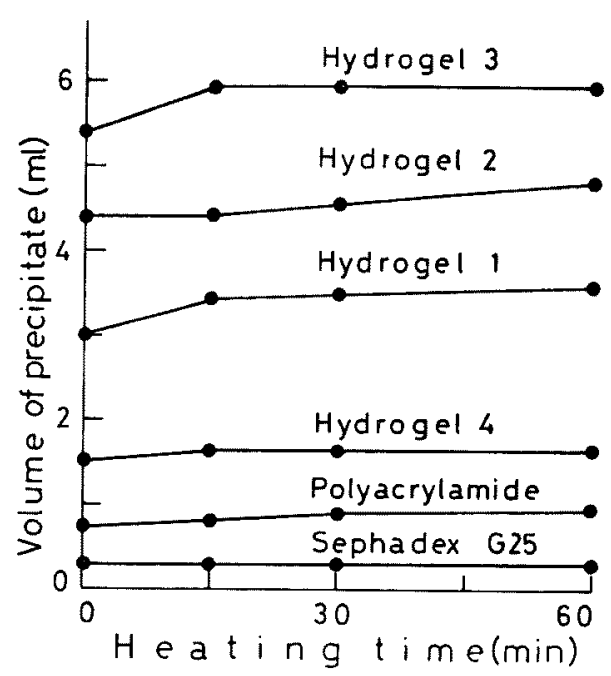

Fig. 4. Effect of heating of high water-uptake hydrogels on their water-holding capacity. Waterholding capacity was expressed as the volume of precipitate after heating at $80^{\circ} \mathrm{C}$ in $3 \% \mathrm{NaCl}$.

Fig. 4 shows the effect of heating of the high water-uptake hydrogels in $3 \% \mathrm{NaCl}$ solution on their water-holding capacity. Hydrogels 1, 2 and 3 showed higher capacity than the others. However, heating time scarcely affected the capacity.

Adhesive force of the pellet to the shio-surimi could not be determined for all the high wateruptake hydrogels except for Hydrogel 4, because their pellet was swollen during heating at $80^{\circ} \mathrm{C}$, and disjointed to particles by stretching. It was observed that the particles did not adhere to the shio-surimi. Only with Hydrogel 4, however, its pellet strongly adhered to the shio-surimi and showed strong adhesive force $(485 \mathrm{~g})$ nearly the same as that of the control $(490 \mathrm{~g})$.

\section{Discussion}

Starch was found from the microscopic observation to exist as gelatinized, swollen granules within the kamaboko.") The powder of polyvinyl alcohol increased both the breaking strength and water-holding capacity of kamaboko.") During compression of starch-containing kamaboko, agreement between the actual and theoretical stressstrain response became less as the starch content was raised.5) The strength of kamaboko containing soybean protein correlated highly with the degree of denaturation of the protein (inversely proportional to the nitrogen dispersible index). ${ }^{0}$ )
Rigidity of the shio-surimi added with the starch was increased when the temperature overcame that for the gelatinization of the starch. ${ }^{7)}$ Thermal transitions of the starch and fish protein monitored by the rigidity and DSC thermograms seemed to proceed independently. ${ }^{7)}$ Furthermore, in a constant rate-heating of the shio-surimi alone and in combination with the egg white and whey protein concentrate, the rigidity and DSC thermograms for the mixtures resembled composites of the individual protein sources profiles. ${ }^{8}$ )

From the above findings, it has been suspected that the gelling substances do not contribute to the myofibrillar protein network structure within the kamaboko and also that they act as a filler reinforcement or water absorbent within the kamaboko.

With respect to the contribution of the gelling substance to the network structure, it has been most recently recognized that while the profitable egg albumin, soybean protein $A_{1}$ and wheat gluten contribute to the network structure, presumably due to hydrophobic interactions, ${ }^{9)}$ this contribution is not always indispensable to the gel-strengthening action. ${ }^{3)}$ Such result would deny the role of gelling substances as an active filler which contributes positively to the network structure within the gel as gravels within a concrete block behave so, that is, the gravels strongly adehere to cement, by which the concrete block is strengthened.

Most recently, it has been found from the DSC analysis that the kamaboko added with the profitable gelling substance contains large amount of captured water within it. ${ }^{1)}$ This result seems to suggest that gelling substances act as water absorbent.

If so, the kamaboko might be strengthened also by the addition of so-called "high wateruptake hydrogel" or "highly swellable electrolyte gel". The purpose of the pressent study is to examine the role of gelling substances as water absorbent within the kamaboko. As understood from the results shown in Figs. 1-3, almost all the high water-uptake hydrogels increased the strage modulus, loss modulus, breaking strength and breaking strain with a few exceptions, and decreased the amount of expressible water.

In such the gel-strengthening action, they were never inferior to the profitable natural high polymers examined previosuly, such as agar, $k$-carrageenan, corn starch, egg albumin, soybean proteins $A_{1}$ and $A_{2}$, and wheat gluten. ${ }^{2)}$ Contribu- 
tion of the high wateruptake hydrogels to the network structure was found to be not always indispensable to the gel-strengthening action also here as understood from the result that the pellet of Hydrogel 4 which was never superior to the other hydrogels strongly adhered to the shiosurimi upon heating. This result also suggests that the gelling substance does not act as the active filler. Considering the above results the gelling substances would cause dehydration and increase the density of the surrounding protein matrix. However, no clear correlationship was detected between the water-holding capacity and gel-strengthening action of the high water-uptake hydrogels as understood from the result that $\mathrm{Hy}$ drogels 1,2 and 3 exhibiting the high waterholding capacity were never superior to the others. For the development of the gel-strengthening action, the gelling substance may be needed to exhibit a good balance between the water-holding capacity and the rigidity of the swollen granules within the kamaboko. The participation of the latter can be presumed from the facts that the kamaboko could not be strengthened by the addition of the pregelatinized starch ${ }^{4)}$ and that with raising starch content, the shear storage modulus of the kamaboko was rapidly decreased above ca. $55^{\circ} \mathrm{C}$ at which the starch became to be gelat- inized. ${ }^{10)}$

This study was partly carried out by the grant of Ajinomoto Co. Ltd.

\section{References}

1) E. Niwa, T. T. Wang, S. Kanoh, and T. Nakayama: Nippon Suisan Gakkaishi, 54, 2139-2142 (1988).

2) E. Niwa, T. T. Wang, S. Kanoh, and T. Nakayama: Nippon Suisan Gakkaishi, 54, 841-844 (1988).

3) E. Niwa, T. T. Wang, S. Kanoh, and T. Nakayama: Nippon Suisan Gakkzaishi, 54, 989-992 (1988).

4) M. Okada: Tokai Reg. Res. Lab., 36, 21-126 (1963).

5) I. Takagi and W. Simidu: Nippon Suisan Gakkaishi, 38, 471-474 (1972).

6) K. Yasumatsu, K. Misaki, T. Tawada, K. Sawada, J. Toda, and K. Ishii: Agr. Biol. Chem., 36, 737-744 (1972).

7) M. C. Wu, T. C. Lanier, and D. D. Hamann: J. Food Sci., 50, 20-25 (1985).

8) J. C. Burgarella, T. C. Lanier, and D. D. Hamann: J. Food Sci., 50, 1588-1594, 1606 (1985).

9) E. Niwa, T. T. Wang, S. Kanoh, and T. Nakayama: Nippon Suisan Gakkaishi, 54, 1851 (1988).

10) M. Hamada and Y. Inamasu: Nippon Suisan Gakkaishi, 50, 537-540 (1984). 